\title{
JEROBOÃO I E OS REIS DE ISRAEL:
}

uma análise dos pressupostos epistemológicos da história deuteronomista

\author{
JEROBOAM I AND THE KINGS OF ISRAEL: \\ an analysis of the epistemological presuppositions of deuteronomist historiography
}

\author{
Vicente Artuso* \\ Luiz José Dietrich** \\ Marcus Vinicius de Souza Nunes ${ }^{* * *}$
}

\begin{abstract}
RESUMO
O estudo apresenta o estado da questão da história deuteronomista na sua relação com o pecado de Jeroboão. O objetivo é destacar o caráter ideológico dos textos na ótica judaísta. O método é analítico e parte da suspeita dos textos que foram escritos com uma ótica antipoliteísta e antissamaritana e, portanto, incapaz de assimilar o modo de produção de conhecimento da própria religião e do reino do norte. Assim a fidelidade ao Deus único e ao seu lugar de culto são os critérios epistemológicos da história deuteronomista. Prevalece uma visão negativa dos reis de Israel. Eles fizeram o mal aos olhos do Senhor como fez Jeroboão. O confronto das avaliações do reino de Judá com as do reino de Israel revela pequenas, mas significativas, contradições. Há uma clara tendência de hostilizar Jeroboão como aquele que fez Israel pecar, enquanto apenas Davi é citado como exemplo positivo. Palavras-chave: Jeroboão. Reis. Deuteronomista. Epistemologia.
\end{abstract}

\begin{abstract}
The study presents the state of the matter of Deuteronomist history in its relation to the sin of Jeroboam. The aim is to highlight the ideological character of the texts from a Jewish perspective. The method is analytical and part of the suspicion of the texts that were written with an antipolitical and anti-samaritan perspective and therefore unable to assimilate the way of producing knowledge of the religion itself and the northern kingdom. Thus, fidelity to the one God and his place of worship are the epistemological criteria of the Deuteronomist historiography. A negative view of the kings of Israel prevails. They did evil in the sight of the Lord as did Jeroboam. The confrontation of the evaluations of Judah kingdom with those of Israel kingdom reveals small but significant contradictions. There is a clear tendency to antagonize Jeroboam as the one who made Israel sin, while only David is cited as a positive example.
\end{abstract}

Keywords: Jeroboam. Kings. Deuteronomist. Epistemology.

\footnotetext{
${ }^{*}$ Doutor em Teologia pela Pontifícia Universidade Católica do Rio de Janeiro, Brasil. Mestre em Ciências Bíblicas no Pontifício Instituto Bíblico de Roma, Itália. Professor do Programa de Pós Graduação em Teologia da Pontifícia Universidade Católica do Paraná. Brasil. ORCID: oooo-0003-3036-1774. Email:vicente.artuso@pucpr.br.

*** Doutor e Mestre em Ciências da Religião pela Universidade Metodista de São Paulo, Brasil. Professor do Programa de Pós Graduação em Teologia da Pontifícia Universidade Católica do Paraná. Brasil. ORCID: oooo-0002-3492-4872. E-mail: luiz.dietrich@pucpr.br.

*** Mestre em Educação e mestrado em andamento em Filosofia pela Universidade Federal de Santa Catarina, Brasil. ORCID: 0000-0002-7340-4642. E-mail: marcus.snunes@gmail.com.
} 


\section{INTRODUÇÃO}

Nosso estudo aborda temas fundamentais na história deuteronomista: a centralização do culto na reforma de Josias e o pecado de Jeroboão e dos reis do norte que resultou na divisão do reino. Iniciamos situando as origens, composição, e significado da história deuteronomista em sua relação com o pecado de Jeroboão e a reforma de Josias. Nas avaliações dos reinados observamos os critérios e motivos que compõem o que aqui chamamos paradigma epistemológico da história deuteronomista. Nosso artigo se compõe de seis partes: 1- Origem e composição da história deuteronomista; 2- Os livros dos Reis; 3A forma literária de 1 e 2 Reis; 4- A avaliação dos reis de Israel; 5- Confronto com a avaliação dos reis de Judá; 6- O pecado de Jeroboão.

Destacamos que fazemos a análise histórica dessa tensão a partir das noções de paradigma epistemológico e epistemicídio. Ademais de um conflito político e religioso, a imagem produzida na narrativa deuteronomista realiza verdadeiro epistemicídio, isto é, parece buscar a eliminação da epistemologia tácita da religião do Norte em detrimento do paradigma epistemológico do Sul, como evidenciaremos mais à frente.

Segundo Römer (2016, p. 124),

há uma relação entre a lei da centralização e a avaliação dos reis que são julgados de acordo com sua lealdade a Javé e ao templo de Jerusalém. O declínio do reino do Norte é explicado em 2 Rs 17, 1-6.18.21-23 como uma consequência da falha dos reis de Israel em se ajustarem à ideia deuteronomista da centralização do culto (RÖMER, 2016, p. 124).

Nesse contexto se entende que as denúncias dos pecados dos reis do Norte, sejam focalizadas na idolatria e no culto nos lugares altos. Mostramos nesse estudo a epistemologia das narrativas que atribuindo repetidamente esses pecados de Jeroboão aos reis do Norte, ofuscam sua grandeza e ele passa a ser o reino esquecido. Quem passa a brilhar é o reino do Sul que teve seu auge com Josias e sua reforma. Ele será elogiado plenamente pois em 2Rs 23,15 destrói o santuário de Betel e põe fim os pecados de Jeroboão seguindo o que prescreve Dt 6,4-5 Jeroboão por sua vez, carrega a pecha de rei que fez o mal, e com ele todos os reis do reino do Norte seguiram sua conduta.

Observamos, que com frequência na avaliação dos reis é dito que fizeram o mal aos olhos do Senhor, sendo esta avaliação complementada com frase acusatória: seguiram os passos de Jeroboão, filho de Nabat que fez Israel pecar. O leitor poderá observar também

\footnotetext{
${ }^{1}$ Todas as referências da Bíblia neste artigo, foram tomadas da BÍBLIA TEB, 1994.
} 
na avaliação dos reinos de Judá, que nenhum rei que fez o mal será citado como exemplo negativo mais de duas vezes. Ao contrário em relação ao reino de Judá, o rei Davi sempre aparece como exemplo positivo na avaliação dos dois reinos. Alguns comentaristas do livro dos reis, por exemplo Donald J. Wiseman (2006, p. 128-129) relatam com fidelidade o pecado de Jeroboão (p. 128-129), mas não comentam as diferenças na avaliação dos reis. A introdução à história deuteronomista de Claudio Balzaretti (2012, p. 350) apenas constata o fato da avaliação positiva e negativa como um detalhe literário e não adentra a reflexão nos motivos do julgamento. Römer (2008, p. 101), explica que o pecado de Jeroboão foi estabelecer uma concorrência ilegítima com o templo de Jerusalém ao construir dois santuários em Dã e Betel. Por esse motivo os reis do Norte são acusados daquilo que é designado como pecado de Jeroboão. Os reis do Sul serão comparados com seu pai Davi (1Rs 15,3.11; 2Rs 14,3; 16,2; 18,3; 22,2 apud RÖMER, 2008, p. 156). No entanto Römer não avalia a culpabilidade diferenciada atribuída aos reis do Norte e a consistência do pecado de idolatria de Jeroboão. Nossa pesquisa é mais abrangente e informa as discrepâncias na avaliação dos reinados confrontando os resultados. Além dessa contribuição, para nós, filosoficamente, importante é considerar os pressupostos dessa história dos reinados e sua consistência epistemológica²: a partir de qual lugar se fala? Mostramos a leitura na ótica do projeto de Josias de unificar o reino em torno de um só Deus e um só lugar de culto. Assim a epistemologia judaíta do sul hostiliza Jeroboão por ser o responsável do cisma entre Israel e Judá tornando-se o exemplo de quem fez Israel pecar.

O leitor há de verificar na insistência dos autores deuteronomistas no pecado de Jeroboão, que eles numa fase final da redação, completaram a história numa ótica judaíta, antipoliteísta e antissamaritana, preocupados em constituir ou justificar a integração política e religiosa de Israel e Judá em uma única unidade governada a partir de Jerusalém.

\section{ORIGEM E COMPOSICÃO DA HISTÓRIA DEUTERONOMISTA}

Martin de Wette em 1805 identificou o livro da Lei (2Rs 22,8) descoberto no templo como a parte central do livro do Deuteronômio (Dt 12 - 26). Mais tarde Julius Wellhausen também identificou textos do livro do Deuteronômio nos profetas anteriores. Porém foi Martin Noth em 1943 quem detectou uma unidade de conteúdo e de composição. Segundo

\footnotetext{
${ }^{2} \mathrm{O}$ conceito de epistemologia que aqui utilizamos se aproxima daquele proposto por Santos, e Meneses em Epistemologias do Sul (2009, p. 10): "Epistemologia é toda noção ou ideia, refletida ou não, sobre as condições do que conta como conhecimento válido. É por via do conhecimento válido que uma dada experiência social se torna intencional e inteligível."
} 
Noth essa unidade entre Deuteronômio e Js, Jz, Sm e Rs deve-se a um autor chamado Deuteronomista. Noth defendeu a existência do tetrateuco ( $\mathrm{Gn}, \mathrm{Ex}, \mathrm{Lv}, \mathrm{Nm}$ ) deslocando o livro do deuteronômio como introdução à história deuteronomista que vai de Js até 2Rs, que se trataria de uma teologia unificada.

Porém a composição dessa unidade é complexa. Estudos recentes mostram que há textos com estilo do deuteronômio espalhados em todo pentateuco. Segundo Paganini (2011, p. 37) há conexões de textos legislativos do Deuteronômio no resto do pentateuco. O Deuteronômio atualiza textos do Êxodo (cf. Dt 15,12-18 com Ex 21,1-11; Dt 18,9-13 com Ex $22,17)$. A composição inclui camadas do tempo do exílio e do pós-exílio. Conforme o modelo de Göttingen proposto por Rudolf Smend e elaborado por W. Dietrich, haveria três camadas principais na história deuteronomista: Um deuteronomista historiador (HDtr) que escreveu no tempo do Exílio; Um deuteronomista profético (DtrP) em Samuel e Reis; Um deuteronomista legislador (DtrN) que nos inícios do pós-exílio insiste na importância da Lei (RÖMER, 2016, p. 115). São teorias muito próximas à tese de Noth e que aprofundam a compreensão da História Deuteronomista composta no período do Exílio Babilônico. De fato, a História Deuteronomista visa explicar os motivos do exílio. Destaca Römer (2008, p. 112) que "a hipótese dos livros de Deuteronômio-Reis como uma história contínua e coerente permanece até hoje como uma das mais importantes teorias da pesquisa do Antigo Testamento”. Römer (2016, p. 118) acata a defesa de uma história deuteronomista (HDtr) no tempo de Josias pois muitos textos e ideias são mais bem entendidos no século VII a.C do que no período exílico. Seus discípulos consideram a primeira edição da história Deuteronomista no período de Josias (640-609), sendo completada depois de 587 com textos do tempo do Exílio. Cross (1973, p. 274-289, apud RÖMER, 2016, p. 113) baseia sua teoria em dois temas centrais: o pecado de Jeroboão (1Rs 12) que representa Javé como um touro e a construção de santuários fora de Jerusalém em Dã e Betel Isso faz sentido para explicar o motivo do exílio e destruição de Jerusalém como resultado do castigo do Senhor pelo pecado: Os reis fizeram o mal aos olhos do Senhor.

\section{O LIVRO DOS REIS}

O livro dos reis (1-2 Rs) narra a história dos reis de Israel e Judá. Inicia narrando o final do reinado de Davi e as intrigas da sua sucessão (972 a.C.) e termina com o exílio de Babilônia (587 a.C.). 1 e 2Rs fazem parte da chamada historiografia deuteronomista, composta pelos livros de Js, Jz, 1-2Sm, 1-2Rs, relacionada ao livro do Deuteronômio. O 
Deuteronômio se origina de uma antiga coletânea de leis (provavelmente contida em Dt 12 - 26) influenciada pelas tradições proféticas do reino do Norte (ROSE, 2010, p. 267). A história de sua composição é complexa iniciando com compilações pré-exílicas, passando por redação e expansão no exílio (586-538) (GRAY, 1977, p. 6), e sendo finalizado com uma terceira redação no período persa (RÖMER, 2008, p. 62-70).

Uma primeira versão de 1-2Rs teria parado no reinado de Ezequias (700 a.C.) (WEIPPERT, 1952, p. 328). Outra parte foi compilada no tempo da reforma de Josias em 622, recebendo acréscimos na sua redação final na época do exílio, por volta de 561 a.C. (EISSFELDT, 1980, p. 227). Mas há também uma camada pós-exílica na historiografia deuteronomista. A ideologia de um único Deus e um único templo, com um discurso teológico mais etnocêntrico que o da Torá, se insere de forma adequada no pós-exílio (KNAUF, 2010, p. 377) quando o povo precisa firmar-se na sua identidade judaíta com o fim das instituições históricas (Estado, Rei, Templo)3. Do ponto de vista da história da redação 1-2Rs revelam uma sólida compacidade, devida a uma clara unidade de propósito e de redação. Essa unidade de propósito da centralização em um só Deus e um só templo vai submeter a múltipla origem de um povo a um único princípio. Para isso se comete a violência da identidade em vista de suprimir o estranho, o outro4. Entretanto nessas narrativas percebe-se também o "caráter compilatório, na frequente desconexão de trechos narrativos, reunidos artificialmente e inseridos muitas vezes com arestas, na moldura histórico-

\footnotetext{
3 Podemos reconhecer na relação Judá-Israel uma tensão epistêmica que, nos faz perceber que os pressupostos epistemológicos deuteronomistas constitui verdadeiro epistemicídio, isto é, não legitimação das categorias da experiência do Norte. Essa tensão se baseia nas oposições, apresentadas na história deuteronomista, a saber: O Reino de Judá privilegia aliança com a casa de Davi (dinastia única) o santuário é central, o sacerdócio é ligado ao templo, a pureza da raça (amixia entre os que voltaram do exílio). No Reino de Israel, destaca-se a aliança Mosaica, há vários santuários, predomina a tradição profética mais que a sacerdotal, há mistura de raças. A chave epistêmica deuteronomista judaíta: um só Deus, um só lugar de culto, tende a ocultar as origens de Israel do Norte por não admitir a pluralidade dos lugares de culto, ou outras formas de manifestação religiosa.

4 Uma chave de leitura para esse processo é a apresentada por Adorno em Dialética Negativa (2009). Todo sistema, monoliticamente construído sobre um único princípio conciliatório tende a, abstratamente, dissolver toda contradição em uma identidade, seja mediada ou não. As imediatas são aquelas que mais facilmente reconhecemos como ideologia, isto é, que percebemos não terem sido submetidas ao crivo da crítica histórica. Porém, sistemas mais elaborados, especialmente os dialéticos que pressupõem um processo contínuo de afirmação e negação, tendem a resolver essas contradições em sínteses superiores. Estas, com dificuldade, surpreendemos-lhes o caráter ideológico. O universal dissolve o particular, seja pela identificação deste com uma parte do sistema, seja pelo epistemicídio, onde o antagonismo é resolvido por eliminação: "Aquilo que reluz como se estivesse acima dos antagonismos equivale ao enredamento universal. $\mathrm{O}$ universal cuida para que o particular submetido a ele não seja melhor que ele mesmo. Esse é o cerne de toda identidade produzida até hoje" (ADORNO, 2009, p. 259). Judá produz sua história não como antagonista particular à particular experiência de Israel, mas eleva o seu princípio (a unicidade) a universal abstrato. Assim, a experiência do Norte é irreconciliável e, por conseguinte, sempre à margem, sempre impura, sempre ilegal. Não há discussão possível entre o particular antagonista e o universal abstrato a partir dos pressupostos que fundam o sistema. É preciso não mais pressupor princípios do sistema, não mais tomálos como evidentes em si mesmos, assim particularizando-os e remetendo-os uma vez mais à esfera do legítimo antagonismo.
} 
teológica do livro” (BALLARINI, 1976, p. 148). Quanto à organização do livro pode-se identificar três partes: A história de Salomão (1Rs 1 - 11); a história paralela dos reinos de Israel e Judá até a queda do reino do Norte Samaria (1Rs 12 - 2Rs 17); a história do reino de Judá até o exílio (2Rs 18 - 25). Há uma ruptura evidente na história dos dois reinos com a inserção do ciclo dos profetas Elias e Eliseu (1Rs 17 - 2Rs 13). Ademais os profetas dominam a história e aparecem no decorrer do livro (Natan, Aías, Semeias, Miqueias, Jonas, Isaías, Hulda) (BALZARETTI, 2012, p. 350 e 356). Isso justifica a classificação desses livros no cânon hebraico entre os profetas anteriores.

Quanto às fontes, os autores possivelmente se serviram de obras pré-existentes. Algumas destas obras são explicitamente citadas, como o livro dos "anais dos reis de Israel" (1Rs 14,19) e dos "anais dos reis de Judá” (1Rs 14,29), e “o livro dos atos de Salomão” (1Rs 11,41). A essas obras dos arquivos reais os autores frequentemente remetem os leitores desejosos de maiores informações. Há também as fontes provindas das tradições proféticas e discute-se a antiguidade de conjuntos textuais como o chamado de História a sucessão de Davi ou História da ascensão de Salomão ao trono (2Sm 9 - 20 e 1Rs 1 - 2).

Mesmo que os livros dos reis sejam ricos de informações históricas, algumas comprovadas pela arqueologia 5 , os estudiosos os consideram mais como uma_historiografia teológica, e não propriamente históricos. Esta é a episteme própria de Israel-Judá: lê sua história com lentes proféticas. A validade epistemológica de Israel é de fato teológica. De preferência esses livros são definidos como "uma reflexão teológica sobre um período da história de Israel em que esse povo era governado por reis” (BÍBLIA TEB, 1994, p. 493). Segundo RÖMER (2008, p. 18), os textos que relatam a história dos dois reinos (1Rs 12 2Rs 17), objeto deste estudo, são escritos numa perspectiva judaíta. Atualmente é quase um consenso entre a pesquisa crítica, que esta história entrecruzando informações do reino de Israel, norte, com as do reino de Judá, sul, não existia antes de Ezequias e de Josias. “Antes do Historiador Dtr, não há qualquer indício de uma historiografia desse tipo em Samuel Reis" (VAN SETERS, 2008, p. 302). Isto é, o que encontramos em 1 e 2Rs é uma construção cultural que configura e apresenta alguns dados do passado, das monarquias do sul e do norte, retroprojetando neles os contextos, interesses, e projetos das cortes do rei Ezequias e do rei Josias, e também dos grupos de exilados e de retornados do exílio.

\footnotetext{
5 A estela de Mesha, rei de Moab, do século IX a.C., confirma a relação entre o povo de Moab e Israel. A inscrição de Siloé do séc. VIII a.C. descreve a realização do canal que conduz água da fonte de Gion para Jerusalém por ordem de Ezequias (2Rs 20,20). Entre os óstraca de Lakish há cartas escritas antes da queda Jerusalém e testemunham o avanço dos babilônios sobre Judá (BALZARETTI, 2012, p. 348-349). A arqueologia encontra pelo menos 31 nomes de reis, faraós e outros personagens citados nos livros dos Reis (MYKYTIUK, 2014, p. 46-47).
} 
Nesta história construída os reis são submetidos a uma avaliação cujos critérios seriam sua fidelidade ao Senhor e sua observância do mandamento da centralização do culto, porém estes dois aspectos só são exigidos dos reis após as reformas de Ezequias e de Josias. Segundo Lohfink (apud KRAMER, 2006, p. 63) se encontram 14 leis de centralização do culto esparsas no livro do Deuteronômio (cf. Dt 12,4.7.8-12.13-19 e 16,1-8.9-12.13-15.1617). Esta insistência da centralização do culto explica também a repulsa e condenação dos lugares de culto fora de Jerusalém ${ }^{6}$, especialmente dos lugares altos (bamôt), relatada no livro dos Reis. Os livros dos Reis foram escritos para mostrar que durante o período da monarquia uma série de infidelidades ao culto do verdadeiro Deus e às prerrogativas de seu Templo levaram à destruição dos dois reinos, apesar dos esforços dos profetas de denunciar os pecados e conduzir o povo no projeto de Javé. Na angústia e dor do exílio, se procura fazer uma revisão da história na tentativa de responder: Por que estas desgraças aconteceram? Onde foi que erramos? Por que fomos castigados duramente? O livro procura responder a estas perguntas apresentando a história da monarquia e fazendo uma avaliação dos reinos numa ótica profética, denunciando as infidelidades à Aliança, causa de todos esses males (Cf. CRB, 1992, p. 36).

A interpretação do acontecimento do Exílio (586-538) à luz do Deuteronômio é aparentemente simples, baseada num princípio religioso: "Isto aconteceu porque os filhos de Israel tinham pecado contra Javé seu Deus que os tirara da terra do Egito" (2Rs 17,7; Cf. Jr 52,3; 2Rs 23,26). Porém, numa análise comparativa da história paralela dos dois reinos, a questão é mais complexa do que aparenta.

$\mathrm{Na}$ avaliação dos reinados se percebe que toda oposição epistemológica que possa ser apresentada na experiência do Norte aparece como fora do discurso normatizante. Mais que isso, é não-normatizável, não pode ser incluída como parte, ainda que defectiva, do sistema judaíta. Assim, toda oposição é sempre cismática, e todo discurso produzido no Norte é alienus, um outro estranho, que não pode ser conciliado, mas pode (e deve) ser condenado, perseguido, injuriado, como um grande exorcismo epistemológico. De fato, o interesse é

\footnotetext{
6 A repulsa também merece uma consideração de tipo filosófico-epistemológico. Adorno e Horkheimer na Dialética do Esclarecimento (1985) fizeram longa consideração sobre o processo de desmitologização, característico do Esclarecimento. Este não pode ser entendido apenas como o movimento iluminista do século XVIII. Segundo eles, é uma tendência inerente à história humana que se apresenta extremamente ativa na ereção de novos sistemas de dominação. A eliminação dos lugares altos pode ser interpretada nessa chave, como um processo de racionalização de uma determinada prática como mais adequada dentro de um determinado sistema: "É dessa separação entre a racionalidade e a irracionalidade do sacrifício que a astúcia se utiliza. Toda desmitologização tem a forma da experiência inevitável da inanidade e da superfluidade dos sacrifícios" (ADORNO, HORKHEIMER, 1985, p. 53). O sacrifício considerado inane é o realizado nos lugares altos. A astúcia consiste em fazer do novo sistema de culto, altamente centralizado, o único válido, à medida que corresponde ao único sistema de poder hierosolimita. Esse culto supérfluo é o objeto de repulsa do esclarecido, daquele que adere ao sistema oficial do sul.
} 
manter as rédeas do poder centralizado em Jerusalém sem a participação popular. Mas esse grupo encontra oposição de membros das tribos do reino do Norte. Os textos sobre o final do reinado de Salomão (1Rs 11) e a divisão do reino (1Rs 12) espelham esses conflitos. A partir da narrativa da divisão a história dos dois reinos revela a ótica judaíta de Jerusalém (1Rs 11,34-36).

O critério da centralização do culto explica por que nenhum rei de Israel pode satisfazer os padrões ideológicos dos redatores finais,7 justamente por causa do cisma. (RÖMER 2008, p. 18). Para os reis de Israel, a condenação é geral: eles fizeram aquilo que é mal aos olhos de Javé, é sempre atrelada à censura de apego ao pecado de Jeroboão (1Rs 15,26.34), enquanto um certo número de reis de Judá, - os mais elogiados são Davi, Ezequias e Josias - é apresentado de forma bem positiva. É possível que na última fase da redação ao elogiar os reis de Judá, e acusar os reis do Norte, o autor quisesse reacender a esperança da volta do poder monárquico sob a dinastia davídica. No final do exílio a lâmpada acesa da dinastia poderia brilhar com a volta de Babilônia do exilado rei Joaquim? Porém o motivo pelo qual os reis do reino de Israel são julgados mais severamente que os reis do reino de Judá, e que Jeroboão seja citado como exemplo negativo, é justamente por ter provocado o cisma político e religioso.

\section{FORMA LITERÁRIA DE 1-2 REIS COMO EPISTEMOLOGIA JUDAÍTA}

Os autores organizam o material das fontes numa moldura ou currículo que marca tanto o início (fórmula introdutória) como o término (fórmula de conclusão) de cada período real (WISEMAN, 2006, p.44). Aqui se situa o princípio arquitetônico da epistemologia que dá unidade a leitura da história a partir do princípio: agir ou não agir de acordo com a vontade de Deus. Esta moldura ou arcabouço em que são inseridas as biografias dos reis são bastante uniformes com poucas variações. Desde a morte de Davi, de Salomão, e de Jeroboão pode-se ler algumas frases semelhantes sobre a duração do reino, a sepultura do rei e o nome do sucessor (Cf. 1 Rs $2,10-12$; 11,41-43; 14,19-20). O molde se torna mais evidente a partir de Roboão (Cf. 1Rs 14,21-22; 14,29-31) (ROBERT-FEUILLET, 1967, p. 434)

BALLARINI (1976, p. 148) apresenta esta moldura de forma resumida com a biografia dos reis: a) Introdução: sincronismo de um rei com o contemporâneo do outro reino; anos

\footnotetext{
7 Nem mesmo o rei Jeú foi poupado. Segundo os textos ele combateu Baal e Asherá e foi um fervoroso javista, porém, isso parece não ter sido suficiente, sua avaliação é negativa porque ele "não se desviou dos pecados que Jeroboão, filho de Nabat fizera Israel cometer" (2Rs 10, 29).
} 
de reinado e, para os reis de Judá, idade da subida ao trono, muitas vezes também o nome da mãe. b) Corpo: Juízo sumário sobre o rei, quase exclusivamente com base em sua atitude religiosa, sobretudo em face do culto mosaico, com referência constante a dois modelos: Jeroboão I, para Israel (exemplo negativo), e Davi, para Judá (exemplo positivo); breves alusões a alguns fatos mais destacados. c)Epílogo: citação das fontes, a que se remete para maiores detalhes; alusão à morte do rei e a seu sepultamento; nome do sucessor.

Manifestamente os reis são avaliados segundo a norma do Deuteronômio que é a Aliança entre Javé e os israelitas (Dt 4,35-40). Os preceitos fundamentais da lei do Deuteronômio são: um só Deus, um só templo - que implicam na proibição de todas as formas de paganismo ambiente - e estabelecem a centralização do culto num santuário único. O Deuteronômio reprova o uso de qualquer tipo de imagens, anuncia a lei da unicidade do santuário, exige a destruição de todos os outros lugares de culto, e funda o monopólio do Templo e do sacerdócio de Jerusalém (Dt 12). Não somente as ideias, mas o estilo e as expressões favoritas do Dt se encontram nos Reis (comparar 1Rs 14,21-24 com Dt 12,2.3.5.29.31). A Lei de Moisés, ou o Livro da Lei (1Rs 2,3; 2Rs 14,6 citando Dt 24,16), não pode ser senão uma parte mais antiga, ou uma redação primitiva do livro do Deuteronômio (WRIGHT, ELLIOTT, 2017, p. 471). Esta lei Josias descobre no Templo e aplica-a na sua reforma. Este fato é objeto de uma narração pormenorizada em 2Rs 22 - 23 (ROBERT, FEUILLET, 1967, p. 436). Josias (640-609 a.C.) com efeito foi o grande responsável pela reforma deuteronomista em 621. A partir do Livro da Lei que teria sido encontrado no templo ele retoma a reforma religiosa, que outrora fora iniciada por Ezequias (728-699a.C.) e interrompida nos reinados de Manassés e Amon, reinados submissos ao império assírio.

\section{AVALIAÇÃO DOS REIS DE ISRAEL}

Após a narrativa do cisma, em que as tribos de Israel se revoltam contra o reinado de Roboão (1Rs 12), o que chama a atenção é o fato de os reis de Israel serem condenados em bloco, por terem imitado o pecado de Jeroboão (1Rs 14,7; 15,16; 16,26; 2Rs 15,9.18.24.28 etc.). Isto é o que indicamos sob a noção de epistemicídio ${ }^{8}$, que passa pelo não reconhecimento da produção de conhecimento religioso do Reino do Norte. Condenar os

\footnotetext{
8 A rigor o epistemicídio é “a supressão dos conhecimentos locais por um conhecimento alienígena” (SANTOS, MENESES, 2009, p. 10). Este é um comportamento que pode ser facilmente reconhecido na postura judaíta em relação a Israel. Apesar de uma origem comum, a epistemologia do Norte sempre será objeto de crítica como algo mestiço, estrangeiro, inferior, que deve ser purificado. O epistemicídio é a incapacidade de compreender "que o mundo é epistemologicamente diverso" (SANTOS, MENESES, 2009, p. 12).
} 
reis do Norte, no contexto do discurso deuteronomista, é declarar a não-validade de toda a experiência alternativa àquela de Judá. Na condenação geral, o autor destaca como foram os pecados se sucedendo num contínuo crescendo. O pecado de Jeroboão consistiu na cisão do reino e do culto oficial deslocado de Jerusalém para os dois santuários de Betel e Dan. Além disso Jeroboão estabeleceu sacerdotes dentre o povo que não eram da família de Levi (1Rs 12,31; 13,33-34). Nesse quadro insere-se o julgamento por boca do profeta Aías: “Tu não foste como meu servo Davi que observou meus mandamentos...Fizeste mais mal que todos os teus antecessores, e chegaste a fazer para ti outros deuses, imagens fundidas" (1Rs 14,8-9). Nadab filho de Jeroboão reinou dois anos. Ele imitou o comportamento do seu pai Jeroboão e o pecado ao qual tinha arrastado Israel (1Rs 15,25-26). Baasa filho de Aías se tornou rei de Israel e massacrou a casa de Jeroboão (1Rs 15,28-29). Fez o mal aos olhos do Senhor e imitou a conduta de Jeroboão e o pecado ao qual ele tinha arrastado Israel (1Rs 15,34). Por intermédio do profeta Jeú são explicitadas as ações más de Baasa. Ele fez o mal e irritou o Senhor, “ornando-se semelhante a casa de Jeroboão, mas também porque exterminou esta casa” (1Rs 16,7). À dinastia de Baasa é acrescentada também a idolatria (hevel/havelim, imagens/coisas vazias, vãs, sem vida, sem força, sem duração) mais grave que o sincretismo religioso: Baasa e seu filho Ela que lhe sucedeu no reinado "irritaram o Senhor Deus de Israel com seus ídolos vãos" (hevel/havelim, cf. 1Rs 16,13). Até mesmo Zambri que reinou apenas sete dias (1Rs 16,15) recebe o julgamento: Ele "imitou a conduta de Jeroboão e o pecado que fizera, levando Israel a pecar" (1Rs 15,19). Selum, cujo reinado durou um mês, foi o único rei que não recebeu nenhuma avaliação (2Rs 15,13-15).

Segundo BALLARINI (1976, p. 149) há um crescimento do mal aos olhos do Senhor na dinastia de Omri tão grande a ponto de tornar oficial o culto de Baal, divindade fenícia (1Rs 16,25.30-33). Por isso o julgamento de Omri é mais duro: "Fez o mal aos olhos do Senhor superando todos os seus antecessores" (1Rs 16,25). "Imitou em tudo a conduta de Jeroboão filho de Nabat” (1Rs 16,26). O rei Omri foi próspero, fundou Samaria ofuscando a capital Jerusalém. O progresso e bem-estar nos reinos de Omri e Acab não são considerados pelos Deuteronomistas. Para eles Acab, filho de Omri foi ainda pior. Além de oficializar o culto ao Baal fenício e à Asherá, casou-se com a princesa fenícia Jezabel. Entende-se por que os reis da dinastia de Omri (Acab, Ocozias, Jorão) recebam avaliações com oráculos de aniquilação. Profecia que se realiza no massacre da família real de Acab por meio de Jeú, que destrói o santuário oficial do culto a Baal e estabelece o Javismo como religião oficial de Israel (2Rs $9-10)$.

Römer (2008, p. 154) observa a partir de Jeú até Faceia a mesma fórmula para o 
julgamento dos reis de Israel: "fez o mal aos olhos de Javé... e não se afastou dos pecados que Jeroboão, filho de Nabat, levou Israel a cometer". Porém o último rei Oséias "fez o que era mau aos olhos do Senhor, mas não como os reis de Israel antes dele (2Rs 17,2). E no comentário final, porém é acrescentado: os israelitas "perseveraram em todos os pecados que Jeroboão cometeu e não se afastaram deles" ( 2 Rs 17,22). Com isso os autores quiseram diferenciar os primeiros nove reis (Jeroboão (1Rs 14,1-19), Nadab (1Rs 15,25-32), Baasa (1Rs 15,33 - 16,6), Zambri (1Rs 16,15-20), Omri (1Rs 16,21-28), Acab (1Rs 16,29-22.40), Acazias (1Rs 22,52-54; 2Rs 1,1-18), Jorão (2Rs 3,1-27), especialmente os da dinastia de Omri. Esses reis andam no caminho de Jeroboão, mas alguns são piores que seus antecessores. A série de reis a partir de Jeú (2Rs 9 - 10), Joacaz (2Rs 13,1-9), Joás (2Rs 13,10-25), Jeroboão II (2Rs 14,23-29), Zacarias (2Rs 15,8-12), Manaém (2Rs 15,16-22), Faceias (2Rs 15,23-26), Faceia (2Rs 15,27-31), fizeram o mal aos olhos do Senhor seguindo Jeroboão (RÖMER, 2008, p. 155).

Com a insistência em julgar os reis de Israel em relação a Jeroboão o autor está reafirmando que a queda do Reino do Norte se deve a introdução dos bezerros de ouro de Jeroboão e o culto de Baal e Asherá. O julgamento elogioso para alguns reis de Judá é manchado porque "os lugares altos não desapareceram e o povo continuou a oferecer sacrifícios e incenso nos lugares altos" (1Rs 22,44; 2Rs 12,4) Por isso "a ideologia de Reis é antipoliteísta, do culto exclusivo em Jerusalém e também antissamaritana" (KNAUF, 2010, p. 377).

\section{CONFRONTO COM A AVALIAÇÃO DOS REIS DE JUDÁ}

Os reis de Judá, julgados em relação a Davi, são divididos em três categorias: maus, por causa do culto idolátrico permitido ou praticado (Abiam, 1Rs 15,3.6; Acaz, 2Rs 16,2-4; Manassés, 2Rs 21,2-9; Joacaz, 2Rs 23,32); bons, por terem atacado o culto à Asherá, embora tenham deixado continuar o culto nos lugares altos (Asa, 1Rs 15,11-15; Josafá, 1Rs 22,43-47, Joás, 2Rs 12,2b-3; Amasias, 2Rs 14,14; Azarias, 2Rs 15,3-4; Joatão, 2Rs 15,34-35); ótimos, por terem combatido a idolatria e o culto nos lugares altos: Ezequias (2Rs $18,3-8)$ e Josias (2Rs 22,2; 23,25).

Na avaliação dos reis de Judá não há insistência em um personagem judaíta como exemplo negativo. Na avaliação de Abiam, por exemplo, um rei de Judá classificado como mau, o autor se limita a dizer: "Imitou os pecados que seu pai cometeu antes dele e seu coração não foi fiel ao Senhor como Davi." (1Rs 15,3). O rei pior avaliado é Manassés: "Ele 
fez o mal imitando as abominações das Nações" (2Rs 21,2), e "fez Judá pecar procedendo mal aos olhos do Senhor" (2Rs 21,16). O seu pecado é bem descrito como "fazer imagem esculpida de Asherá", (2Rs 21,7: pesel) e de ter feito Judá pecar com seus ídolos (2Rs 21,11: gilulim, ou shiquts, cf. 2Rs 21,21, que são também associados às abominações: to'evah (sing.)/to'evot (pl.) em 2Rs 21,2), sobretudo por promover cultos fora de Jerusalém e a outras divindades além de Javé (2Rs 21,4). Também Amon filho de Manassés "Fez o mal aos olhos do Senhor como fez seu pai Manassés" (2Rs 21,20). Por isso o autor deuteronomista julga negativamente os últimos reis de Judá que seguiram seu pai, exceto Josias que "imitou em tudo o comportamento de Davi seu pai” (2Rs 22,2). Joacaz: "fez o mal aos olhos do Senhor, como haviam feito seus pais" (2Rs 23,32). Joaquim fez o mal aos olhos do Senhor como o haviam feito seus pais" (2Rs 23,37). Sedecias "fez o mal aos olhos do Senhor como fez Joaquim" (2Rs 24,19). Observemos que Manassés nas avaliações negativas dos seus sucessores apenas é citado no curto reinado de Amon. 9

Em relação ao Reino do Norte, o rei Jeroboão e os reis de Israel são majoritariamente citados como exemplos negativos. O autor cita 24 vezes Jeroboão, como o responsável pelo pecado que arrastou o seu povo (cf. 1Rs 13,33-34; 14,9.16; 15,26.34; 16,2-3.7.19; 16,26.31; $22,53$; 2 Rs 3,$3 ; 10,31 ; 13,2.6 .11 ; 14,24 ; 15,9.18 .24 .28 ; 17,21-22)$. Há de se considerar, no entanto certas contradições na menção de Jeroboão e dos reis de Israel como exemplos negativos na avaliação dos reis de Judá.

Alguns reis de Judá tiveram uma avaliação negativa, mas essa avaliação negativa não advém de terem seguido a algum rei mau de Judá, que recebera uma reprovação. Jorão, rei de Judá, $(2$ Rs 8,18$)$ é avaliado negativamente porque fez o mal e imitou o comportamento dos reis de Israel, pelo fato de ter se casado com Atalia da casa de Omri do reino de Israel! Acazias $(2 \mathrm{Rs} 8,27)$ também fez o mal aos olhos do Senhor, mas a exemplo de Acab rei de Israel. Jorão e Acazias são reis de Judá em um momento em que Judá é vassalo aliado da casa de Omri (RÖMER, 2008, p. 156). São avaliados negativamente porque seguiram os passos dos reis considerados separatistas e apóstatas pelos redatores deuteronomistas. De Acaz, rei de Judá, (2Rs 16,2) também é dito que "não fez o que é agradável aos olhos do Senhor como fez Davi” (de Judá, exemplo positivo), mas imitou a conduta dos reis de Israel (exemplo negativo).

Manassés (2Rs 21,2), é o rei de Judá que recebeu a pior avaliação. Fez o mal, fabricou e prestou culto à Asherá como fez Acab rei de Israel (aqui se entende que Acab teve conduta

\footnotetext{
9 Não é tão explícito, como afirma WISEMAN (2006, p. 47) que "na avaliação os últimos reis de Judá foram comparados a Manassés" uma vez que ele é citado apenas no reino de seu filho Amon. E Sedecias, filho de Josias, é mal avaliado por ter feito o mal como seu pai (antecessor) Joaquim.
} 
pior que Jeroboão). Naturalmente se Acab foi pior que Jeroboão, de ora em diante seria Acab quem deveria ser citado como exemplo negativo e não mais Jeroboão, mesmo para o reino de Judá. Jorão, “fez o mal, não como seu pai e sua mãe, pois derrubou a estela de Baal que seu pai (Acab) tinha feito [...] mas continuou apegado aos pecados de Jeroboão" (2Rs 3,1-3). O rei Jeú recebe um leve elogio por ter exterminado o culto oficial a Baal, com o apoio do profeta Eliseu. Se Jeroboão incentivou a idolatria como o autor relata, e Jeú conseguiu exterminar o culto a Baal, como explicar o juízo sobre Jeú que não se afastou dos pecados que Jeroboão fizera Israel cometer (2Rs 10,28-31)? O que levanta a questão: qual seria o pecado de Jeroboão lembrado com tanta insistência? Esta pergunta é fundamental do ponto de vista epistemológico.

Se voltarmos à narrativa da divisão do reino, as ações de Roboão rei de Judá são bem mais caracterizadas como idolatria que Jeroboão. Além de construir lugares altos e Asherás, é dito que em seu tempo existiam até pessoas consagradas ao culto de Asherá10 na terra. Ele imitou a abominação das nações (1Rs 14,22-24). No entanto Roboão não é citado nominalmente na avaliação negativa do seu sucessor Abiam (1Rs 15,3). A categoria epistemológica fundamental de avaliação não é, ao que parece, a idolatria, mas a capacidade de submeter-se ou não ao princípio de unidade da epistemologia judaíta que é a submissão à autoridade central (um templo, um rei, uma lei, uma nação).

Essas contradições mostram que a condenação de Jeroboão é reforçada por ter afastado Israel do templo de Jerusalém e não apenas por causa da idolatria (PIXLEY, 1990, p. 49). Se a idolatria fosse o motivo do mau exemplo de Jeroboão também outros reis que se comportaram pior que Jeroboão seriam também mencionados no seu pecado. Nesses textos vê-se o profundo ressentimento do deuteronomista contra o reino do norte. Os reis de Israel, são eles os pecadores, maus exemplos, enquanto o exemplo positivo, modelo a seguir é Davi do reino do Sul. Aí está patente a teologia davídica, cuja promessa jamais seria cancelada (2Sm 7; Sl 2; 89; 132). Mesmo com os pecados dos reis de Judá, a lâmpada, isto é a dinastia de Davi, não poderia desaparecer (1Rs 15,4; 11,36; 2Rs 8,19; 2Sm 21,17).

\section{O PECADO DE JEROBOÃo}

O pecado segundo o autor deuteronomista foi o fato de ele ter colocado um bezerro

\footnotetext{
10 O hebraico qadesh, erroneamente traduzida como prostituto, literalmente significa pessoa sagrada, ou consagrada, vinculada a uma determinada divindade ou culto. Em Gn 38,21-22 encontra-se a forma feminina qedeshá. (DIETRICH, 2016, p. 103-125). Para Römer (2008, p. 156) as mulheres e os homens assim caracterizados estavam ligados ao culto à Asherá.
} 
de ouro em Betel e outro em Dã (1Rs 12,29-30)11. Seriam esses bezerros realmente ídolos? Sua interpretação é "difícil e controvertida" (DONNER, 1997, p. 283)12. Pode tratar-se do símbolo de um dos deuses cananeus da tempestade, mas para os Israelitas ele é apresentado como o Deus estatal Javé. Aqui o touro dourado serve de pedestal para o invisível Deus de Israel, assim como a Arca em Jerusalém servia como o trono de Deus. Isso parece demonstrável em 1Rs 12,28b se interpretar eloheyka como singular. Ao apresentar os bezerros, Jeroboão diz: "Israel eis o teu Deus que te fez subir da terra do Egito" (SOGGIN, 1984, p. 300-301). Nesse sentido o próprio Jeroboão pode não ter pretendido qualquer tipo de antijavismo (WISEMAN, 2006, p. 128). Aqui seria outro javismo, não alinhado com a teologia judaíta da centralização do culto? Parece que a questão não é estritamente religiosa. Antes de tudo sua intenção era política para separar Israel de Jerusalém. No entanto, no contexto deuteronomista, e também fazendo jus ao hebraico, uma vez que o verbo está no plural (que te tiraram do Egito), indicando um sujeito plural, a tradução de 1Rs 12, 28b no plural: "Eis os teus deuses Israel”, é mais adequada. Coaduna-se melhor com o projeto deuteronomista de rechaçar o politeísmo ou polijavismo das imagens diversas de Deus (RAINER, 1999, p. 266). Essa situação parece ser clara se somarmos várias ações de Jeroboão como: a intensificação do culto nos lugares altos (1Rs 13,31) a nomeação de sacerdotes não levíticos (1Rs 12,31) contrariando Dt 18,1-8; deslocamento da festa das Tendas do sétimo para o oitavo mês (1Rs 12,32) diferente da costumeira data em Jerusalém (Lv 23,24.34-35). Segundo WISEMAN (2006, p. 129) “todas essas ações constituíram o pecado de Jeroboão. Essas práticas instituídas implicaram que os assuntos civis fossem considerados mais importantes do que a prática e os princípios religiosos.”

De fato, segundo a narrativa, a intenção de Jeroboão era impedir o povo de subir a Jerusalém (1Rs 12,26-27). O estabelecimento dos santuários em Dã e Betel visava reforçar a separação de Jerusalém para que o povo não voltasse a casa de Davi (1Rs 12,26). Portanto o pecado do qual Jeroboão é acusado é a cisão da unidade do povo de Deus tanto fisicamente (1Rs 12,25-26) como espiritualmente (1Rs 12,26-27). Essa medida é resultado de uma ação planejada resultando no cisma do reino após a morte de Salomão (931 a.C.). O movimento teve o apoio inicial do profeta Aías de Silo. O cisma foi propriamente político na origem,

\footnotetext{
11 Além dos Santuários de Dã e Betel, Jeroboão fortificou Siquém e Penuel (1Rs 12,25), lembrados pela tradição como locais de teofanias (Gn 33,18-20; 32,25-32), pode ser, portanto, que também funcionassem como santuários; e pode ainda ter identificado sua residência privada em Tirza (1Rs 12,25; 14,17) com o santuário central do reino (RAINER, 1999, p. 265).

12 Donner (Vol. 2, 1997, p. 283) elenca várias interpretações: a) Estandarte de deuses, isto é, símbolos taurinos presos em varas ou barras; b) Pedestais em forma de animal sobre os quais se imaginava a presença invisível de Deus; c)Deus da tempestade originalmente representado por um touro.
} 
causado pela revolta popular contra os impostos e trabalhos forçados vigentes desde o tempo de Salomão.

Pode-se interpretar a recorrente citação de Jeroboão como exemplo negativo, como vinculação, reforço e legitimação dos projetos centralizadores de Ezequias e de Josias. Assim a teologia deuteronomista é marcada pelo reforço ideológico de um projeto de poder que media epistemologicamente um só rei, um só templo, um só Deus. No entanto, os elogios aos reis do Reino do Sul, Asa, Josafá, Joás, Amasias, Azarias e Joatão, são feitos com ressalvas. Eles fizeram o que é agradável e reto aos olhos de Javé, mas não conseguiram eliminar o culto nos lugares altos (1Rs 15,11-12; 22,43-44; 2Rs 12,3). Esse culto um tanto afastado de Jerusalém, e de tendência sincretista com o culto de Baal, segundo os deuteronomistas, constituía um perigo para a pretendida unidade do reino. Os deuteronomistas, à primeira vista, sublinham seu combate ao sincretismo religioso e a idolatria. Porém, o propósito é a reunificação político e religiosa do reino em torno de Jerusalém. Mesmo a avaliação positiva de alguns reis de Judá, com a ressalva da continuidade dos sacrifícios e culto nos lugares altos, indica que eles não conseguiram reunificar o reino.

Em relação aos reis de Israel, o discurso religioso, com julgamento severo por terem seguido os passos de Jeroboão, é uma espécie de advertência à comunidade Israelita, visa legitimar projeto de unidade baseada na observância da lei e centralidade do culto imposto por Ezequias e Josias. O poder centralizado, produzido como identidade, se impõe como discurso teológico que legitima o poder. Não é o teológico em si mesmo que é legitimador, mas o discurso, que se apresenta como identidade abstrata, isto é, sem diferenças, sem capacidade de acolher a diferença, o negativo, o contraditório (ADORNO, 2009). A idolatria torna-se a grande chave de leitura. O idólatra é aquele que insere uma diferença real epistemológica no conceito aparentemente fechado e realizado sobre si mesmo. Mais que adotar outros cultos, é aquele que levanta um questionamento profundo à pretensa unidade sem diferenças do sistema judaíta.

Os reis que foram bons, segundo o deuteronomista, destruíram a idolatria, o culto estranho e seguiram o exemplo de Davi. Os reis de Israel que fizeram o mal aos olhos do Senhor é porque imitaram Jeroboão que fez Israel pecar. Algo semelhante acontece na história da revolta de Coré, Datã e Abiram (Nm 16 - 17) escrita na ótica do poder sacerdotal. Eles se levantaram contra o poder centralizado representado por Moisés e Aarão. E essa reclamação e revolta era fundada nos princípios do deuteronômio que dá voz e vez à comunidade pois ela é santa e o Senhor está no meio de todos (ARTUSO, 2008, p. 16 e 72). 
Estes líderes comunitários por terem se revoltado também foram hostilizados e aniquilados. Esta história de revolta fracassada dos líderes com o castigo divino serve de advertência para que ninguém se revolte contra as autoridades constituídas (Dt 11,6-7; Sl 106,17-18).

\section{CONSIDERAÇÕES FINAIS}

No processo epistemicida do Sul, relativo ao Norte, Jeroboão I é assimilado como contradição, melhor dito, não é assimilado. É o paradigma do não integrado ao sistema. O Deuteronomista cria um sistema, uma epistemologia fechada sobre a interpretação da história do Sul, daí o motivo do autor insistir reiteradamente que Jeroboão fez o mal aos olhos do Senhor. Observamos que no relatório das apreciações negativas dos reinos do norte, nenhuma vez um rei do reino de Judá é mencionado como exemplo negativo. Porém Jeroboão que liderou a revolta das tribos de Israel sempre é lembrado como aquele que fez o mal aos olhos do Senhor. Sabe-se que os redatores falam de Omri e Acab, como reis de Israel que fizeram mais mal que todos os reis anteriores. Se o pecado e idolatria, foi maior que todos os outros porque é acrescentado na avaliação de seus reinados de que imitaram em tudo a conduta de Jeroboão filho de Nabat (cf. 1Rs 16,26.31)? Jeroboão de fato carrega a culpa de ter feito o mal aos olhos do Senhor e ter conduzido Israel a pecar. Qual a diferenciação do pecado de Jeroboão se nos reinados dos seus sucessores houve um crescendo do simples sincretismo para a idolatria e culto institucionalizado a Baal e Asherá?

$\mathrm{Na}$ apreciação dos reinos do Sul, algumas vezes o autor deuteronomista cita como exemplo negativo os reis do Reino do Norte. É o caso de Jorão filho de Josafá que imitou o comportamento dos reis de Israel $(2 \mathrm{Rs} 8,18)$. Ocozias fez o mal aos olhos do Senhor e imitou a família de Acab rei de Israel (2Rs 8,27). Acaz filho de Joatão de Judá não fez o que é agradável aos olhos do Senhor, mas imitou a conduta dos reis de Israel (2Rs 16,3-4). Possivelmente essas avaliações foram produzidas após a queda da Samaria, e aplicadas a reis de Judá, preparam a avaliação ultra negativa de Manassés que justificará também a destruição de Jerusalém (2Rs 21,7-15), escritas, portanto, após a invasão babilônica.

A tendência de repetir os exemplos maus dos reinos do norte como culpados tem conotação mais política que religiosa. A acusação de que os santuários de Dã e Betel afastaram o povo de Israel do santuário de Javé em Jerusalém, significa que eles romperam com o reino unido. Assim o autor comenta "Ele (Jeroboão) com efeito havia separado Israel da casa de Davi e Israel o tinha proclamado como rei Jeroboão" (2Rs 17,21) Depois acrescenta “Jeroboão afastou Israel de Javé e levou-o a cometer grande pecado" (2Rs 17,22). 
Este tipo de avaliação deve ter servido aos propósitos josiânicos, de anexar as terras do reino do norte aos domínios da casa davídica de Judá.

Na avaliação do reino de Judá os exemplos negativos citados são mais raros e não são repetidos. Porém sempre é lembrado o exemplo positivo de Davi, tanto para os reis de Israel como para os reis de Judá. Para os reinos do Norte, Jeroboão é citado 19 vezes como exemplo negativo. Portanto o fazer o mal aos olhos do Senhor parece revelar algo mais que pecados de idolatria com o culto a Baal e Asherá. A gravidade do pecado atribuído a Jeroboão está no cisma político junto com o cisma religioso que a ele são imputados pelas redações deuteronomistas, e que foram mantidos por todos os reis nortistas posteriores a Jeroboão.

A imagem de Jeroboão julgado repetidas vezes como aquele que fez o mal aos olhos do Senhor e fez Israel pecar, caracteriza o cisma político como uma ruptura com a casa de Davi e consequentemente mostrada como uma ruptura com Javé. Impingiram a culpa a Jeroboão e o grupo dos revoltosos, no momento que o reino após a morte de Salomão necessitava de reformas. O clamor vinha do povo e seus representantes que não foram ouvidos. A historiografia deuteronomista tentou abafar um movimento que naquele contexto fora profético. Isso aparece numa espécie de criminalização, com o aumento da culpa dos responsáveis, o que poderia dificultar de interpretar a revolta que levou a divisão dos reinos como sinais de uma urgência de revisão à luz do código da Aliança. Ali é acentuado que a observância da aliança requer a escuta do clamor dos oprimidos (Ex 22,2023). Para os deuteronomistas o cisma significou o rompimento do reino davídico e desestabilização entre as tribos, ofuscando o reino de Judá com o qual fora selada uma aliança eterna (2Sm 7). Porém, a revolta das tribos tendo à frente Jeroboão com o apoio do profeta Aías, fora causada pela insatisfação diante de pesados tributos e a corveia que pesava sobre as tribos. Uma atitude profética e manifestação popular legítima diante das injustiças. Os representantes do povo não foram ouvidos pelo rei Roboão. Houve então a divisão do reino. O grande peso negativo atribuído ao reino de Jeroboão como fruto da ruptura com a casa davídica revela o comprometimento das redações deuteronomistas pré-exílicas com os projetos expansionistas do rei Josias, que foi morto em Meguido (2Rs 23,29-30), buscando afirmar seu controle sobre as terras do antigo reino de Israel.

O estudo das avaliações permite perceber também indícios das camadas redacionais da chamada História Deuteronomista. A recriminação pelo pecado de não eliminar os lugares altos (bamôt), de cultuar outros Deuses ('elohim 'aherim) ou mandar fazer imagens esculpidas (pesel) de Asherá, está vinculada às redações pré-exílicas, do período de Ezequias ou de Josias, ainda numa concepção teológica monolátrica. Enquanto a acusação de seguir 
ou venerar gilul-gilulim (1Rs 15,12; 21,26; 2Rs 17,12; 21,11.21; 23,24) ou shiquts (1Rs 11,5; 11,7; 2Rs 23,13) que indicam objetos detestáveis e de caráter claramente pejorativo, que descrevem bem os objetos proibidos considerados ídolos, indicam camadas redacionais pósexílicas, possivelmente dentro do período persa. Já dentro do monoteísmo como religião oficial, tais objetos perdem qualquer caráter divino, ou virtuoso e são associados frequentemente a outras práticas consideradas abomináveis (to'evah, abominação, ou to'evot, abominações), conforme 1Rs 14,24; 2Rs 16,3; 21,2; 23,13), ou então esvaziadas de qualquer essência divina e chamadas de hevel (sing.)/ havelim (pl.), coisas vãs, vazias (1Rs 16,13).

Nesse projeto de volta ao javismo, não parece que houve uma pureza de religião ritual e social no Sul. Os ritos religiosos, crenças do norte jamais foram integrados como uma contradição própria, inerente do sistema de pensamento programado pelo Deuteronomista como autoimagem de Judá. A contradição é representada como fora do sistema e por conseguinte como verdadeira oposição em um duplo movimento epistêmico: 1) O conhecimento do Norte não é assimilado pelo Sul. O Norte é sempre o outro, mas não outro pleno, alteridade para o sujeito, mas do outro alienus, estranho. Ele pode ser hostilizado, odiado, conquistado e até eliminado porque não está na mesma estatura do sujeito pleno do sul. 2) Assim sendo, o rei Jeroboão I, do norte, passa a ser apresentado como o antimodelo. Discursos de poder e a produção do conhecimento sobre si mesmo se encontram. Nesse caso toda a contradição não superada é proposta como um problema do reino do Norte, ao molde de Jeroboão sendo apresentado como anti-Davi. Estamos diante de uma historiografia política e teológica não isenta de ideologia do poder pois seus representantes buscam legitimar a sua concentração em Jerusalém.

\section{REFERÊNCIAS}

ADORNO, Theodor. Dialética Negativa. Rio de Janeiro: Zahar, 2009.

ADORNO, Theodor; HORKHEIMER, Max. Dialética do Esclarecimento. Rio de Janeiro: Zahar, 1985 .

ARTUSO, Vicente. A revolta de Coré, Datã e Abirã. Análise Estilístico-narrativa e interpretação. São Paulo: Paulinas, 2008.

BALLARINI, Teodorico. Introdução à Bíblia, vol. II/2, Josué, Juízes, Samuel e Reis. Petrópolis: Vozes, 1976.

BALZARETTI, Claudio. Le storiografie della Bibbia. In: BORGONOVO, Gianantonio e 
collaboratori. Logos, corso di studi biblici 2, Torah e storiografie dell'antico testamento. Torino: Editrice ELLE DI CI: Torino, 2012.

BÍBLIA TEB. Tradução Ecumênica da Bíblia. São Paulo: Loyola, 1994.

CRB, (Conferência dos Religiosos do Brasil). A leitura Profética da História. In: Coleção Tua Palavra é Vida, vol. 3, São Paulo: Loyola, 1992.

DIETRICH, Luiz José. "Prostituta" ou "mulher sagrada"? A tradutologia de Antoine Berman e a tradução da Bíblia. In: Rev. Pistis \& Praxis, Curitiba, v. 8, n. 1, p. 103-125, jan./abr., 2016.

DONNER, Herbert. História de Israel e dos povos vizinhos. Vol. II: Da época da divisão do reino até Alexandre Magno. Petrópolis/São Leopoldo: Vozes/Sinodal, 1997.

EISSFELDT, Otto. Introduzione all'Antico Testamento, vol. II. Brescia: Paidéia, 1980.

GRAY, John. I \& II Kings. Old Testament Libery. London: SCM Press LTD, 1977.

KNAUF, Ernest Axel. 1-2 Reis. In: RÖMER, Thomas; MACCHI, Jean-Daniel; NIHAN, Christophe (orgs.) Antigo Testamento história, escritura e teologia. São Paulo, Loyola, 2010, p. 369-380.

KRAMER, Pedro. Origem e legislação do Deuteronômio. Programa de uma sociedade sem empobrecidos. São Paulo: Paulinas, 2006.

MYKYTIUK, Lawrence, Archaeology confirms 50 real people. In: Biblical Archaeology Review, March/April, 2014, Vol. 2, p. 42-50.

PAGANINI, Simone. Deuteronomio. Nuova versione, introduzione e commento. Milano: Paoline Editoriale Libri, 2011.

PIXLEY, Jorge. A História de Israel a partir dos pobres. Petrópolis: Vozes, 1990.

RAINER, Albertz. Historia de la religión de Israel en tiempos del Antiguo

Testamento. Vol. 1. De los comienzos hasta el final de la monarquia. Madrid: Editorial Trotta, 1999.

ROBERT e FEUILLET, Introdução à Bíblia, Antigo Testamento, vol. I. São Paulo: Herder, 1967.

RÖMER, Thomas. A chamada história deuteronomista. Introdução sociológica, histórica e literária. Petrópolis: Vozes, 2008.

RÖMER, Thomas. A origem de Javé. O Deus de Israel e seu nome. São Paulo: Paulus, 2016.

ROSE, Martin. Deuteronômio. In: RÖMER, Thomas; MACCHI, Jean Daniel; NIHAN, Christophe. Antigo Testamento. História, escritura e teologia. São Paulo: Loyola, 2010, p. 260-279. 
SANTOS, Boaventura de Sousa; MENESES, Maria Paula. Epistemologias do Sul. Coimbra: Edições Almedina, 2009.

SOGGIN, Alberto. Storia d'Israele. Brescia: Paidéia Editrice, 1984.

VAN SETERS, John. Em busca da História. Historiografia no Mundo Antigo e as origens da História Bíblica. São Paulo: EDUSP, 2008.

WEIPPERT, H. Die “deuteronomistichen” Beurteilungen der Könige von Israel und Juda und der problem das Redaktion der Köningsbücher. In: Bíblica, 53 (1952), 301-339.

WISEMAN, Donald J. 1 e 2Reis. Introdução e comentário. Série Cultura Bíblica, n. 9, São Paulo: Vida Nova, 2006.

WRIGHT, J. Edward; ELLIOTT, Mark. Israel and Judah under Assyria's thumb. In: EBELING, Jennie; WRIGHT, J. Edward; ELLIOTT, Mark; FLESHER, Paul V. M. The Old Testament in Archaeology and History. Texas: Baylor University Press, 2017, p. 433475 .

Recebido em: 28-02-2019 Aprovado em: 05-09-202O 